\title{
Contaminação Bacteriológica dos Aparelhos Celulares de Acadêmicos de Saúde de um Centro Universitário do Recife - PE
}

\author{
Bacteriological Contamination of Cell Phones of Health Students at a University Center in Recife -
}

PE

\section{Contaminación Bacteriológica de Dispositivos Celulares de Estudiantes de Salud de un Centro}

Universitario de Recife - PE

Julio Eduardo Barbosa da Silva

ORCID: https://orcid.org/0000-0001-6101-0606 Centro Universitário São Miguel, Brasil E-mail: Julio_barbosa100@outlook.com

Angélica Maria Teotônio Cabral ORCID: https://orcid.org/0000-0003-4928-3454 Centro Universitário São Miguel, Brasil E-mail: angelicateotonio@ hotmail.com

Rayssa Rosendo Alves

ORCID: https://orcid.org/0000-0003-3638-167X Centro Universitário São Miguel, Brasil E-mail: rayssa15.ra76@gmail.com

Luana Bastos da Silva

ORCID: https://orcid.org/0000-0002-7069-0567 Centro Universitário São Miguel, Brasil E-mail: lua.bastossilva@gmail.com

Athila da Costa Silva

ORCID: https://orcid.org/0000-0003-0991-8726 Centro Universitário São Miguel, Brasil

E-mail: Athiladacosta@gmail.com

Maria Luiza Ribeiro Bastos da Silva

ORCID: https://orcid.org/0000-0002-8406-9472 Centro Universitário São Miguel, Brasil E-mail: luizabastos6@yahoo.com.br

\begin{abstract}
Resumo
Com a facilidade da utilização do aparelho celular o telefone é levado para os diversos lugares, sendo que alguns deles contém microrganismos patogênicos, como por exemplo, banheiros, hospitais e laboratórios. Os aparelhos celulares podem ser contaminados por bactérias e fungos infecciosos. Dessa forma, o presente estudo objetivou identificar os microrganismos presentes em aparelhos celulares de acadêmicos de saúde de um Centro Universitário de Recife - PE. Trata-se de um estudo transversal quantitativo realizado em março de 2020. Foram coletadas 30 amostras de aparelhos celulares de acadêmicos do curso de Biomedicina. Na apuração de dados através do questionário, cerca de $100 \%$ dos acadêmicos afirmaram saber da presença de microrganismos nos celulares, porém, $15 \%$ dos acadêmicos não lavam as mãos antes das refeições, $81 \%$ se alimentam com o celular ao lado, e apenas $4 \%$ lavam as mãos e se alimentam sem a proximidade do aparelho. A causa mais comum de contaminação de aparelhos celulares é a falta de higienização dos celulares e das mãos. Como resultado dos testes, $100 \%$ dos aparelhos celulares coletados tiveram crescimento microbiológico, sendo $52 \%$ gram-positivas e $48 \%$ gram-negativas. Para as bactérias gram-positivas foram realizados testes de Catalase, cujo $48 \%$ foram positivos afirmando ser Staphylococcus sp e $4 \%$ negativos afirmando ser Streptococcus sp. Nos resultados de Catalase positivas foram feitos testes de Coagulase com 30\% dos resultados positivos, supondo a presença de Staphylococcus aureus. Essas bactérias podem ser agentes patogênicos, ou seja, alteram o funcionamento do corpo causando enfermidades. De acordo com os resultados obtidos, todos os aparelhos testados apresentaram contaminação bacteriana pelos gêneros Streptococcus spp. e Staphylococcus spp. Existem ainda a presença de bactérias da família Enterobacteriaceae como os gêneros Salmonella sp., Klebsiella sp., e a espécie Escherichia coli, mesmo a grande maioria dos acadêmicos afirmando a higienização dos aparelhos.

Palavras-chave: Estudantes; Smartphone; Staphylococcus aureus; Enterobactérias.
\end{abstract}




\begin{abstract}
With the ease of using a cell phone, the phone is taken to many different places, some of which contain pathogenic microorganisms, such as bathrooms, hospitals, and laboratories. Cell phones can be contaminated by infectious bacteria and fungi. Thus, the present study aimed to identify the microorganisms present in cell phones of health students from a University Center in Recife - PE. This is a quantitative cross-sectional study carried out in March 2020. Thirty samples were collected from cell phones of students from the Biomedicine course. However, $15 \%$ of the students did not wash their hands before meals, $81 \%$ ate with the cell phone beside them, and only $4 \%$ washed their hands and ate without the proximity of the device. The most common cause of contamination of mobile devices is the lack of sanitation of the cell phones and hands. As a result of the tests, $100 \%$ of the cell phones collected had microbiological growth, $52 \%$ being gram-positive and $48 \%$ gram-negative. For the gram-positive bacteria, Catalase tests were performed, of which $48 \%$ were positive stating that they were Staphylococcus sp and $4 \%$ negative stating that they were Streptococcus sp. In the positive Catalase results, Coagulase tests were performed with $30 \%$ of the positive results, assuming the presence of Staphylococcus aureus. These bacteria can be pathogens, that is, they alter the functioning of the body causing illness. According to the results obtained, all the devices tested presented bacterial contamination by Streptococcus spp. and Staphylococcus spp. There was also the presence of bacteria from the Enterobacteriaceae family, such as Salmonella sp. and Klebsiella sp.
\end{abstract}

Keywords: Students; Smartphone; Staphylococcus aureus; Enterobacteriaceae.

\begin{abstract}
Resumen
Con la facilidad de usar un teléfono móvil, éste se lleva a muchos lugares diferentes, algunos de los cuales contienen microorganismos patógenos, como baños, hospitales y laboratorios. Los teléfonos móviles pueden estar contaminados por bacterias y hongos infecciosos. Así, este estudio tuvo como objetivo identificar los microorganismos presentes en los teléfonos móviles de los estudiantes de salud de un Centro Universitario en Recife - PE. Se trata de un estudio cuantitativo transversal realizado en marzo de 2020. Se recogieron 30 muestras de los teléfonos móviles de los estudiantes del curso de Biomedicina. En la comprobación de los datos a través del cuestionario, cerca del $100 \%$ de los alumnos afirmó conocer la presencia de microorganismos en los teléfonos móviles; sin embargo, el 15\% de los alumnos no se lavaba las manos antes de las comidas, el $81 \%$ comía con el teléfono al lado y sólo el $4 \%$ se lavaba las manos y comía sin la proximidad del aparato. La causa más común de contaminación de los dispositivos móviles es la falta de desinfección de los teléfonos móviles y de las manos. Como resultado de las pruebas, el 100\% de los móviles recogidos presentaban crecimiento microbiológico, siendo el $52 \%$ grampositivos y el $48 \%$ gramnegativos. Se realizaron pruebas de catalasa a las bacterias grampositivas, de las cuales el $48 \%$ fueron positivas, indicando que se trataba de Staphylococcus sp, y el $4 \%$ negativas, indicando que se trataba de Streptococcus sp. Se realizaron pruebas de coagulasa a los resultados positivos de la catalasa, siendo el $30 \%$ de los resultados positivos, suponiendo la presencia de Staphylococcus aureus. Estas bacterias pueden ser agentes patógenos, es decir, alteran el funcionamiento del organismo causando enfermedades. Según los resultados obtenidos, todos los dispositivos analizados presentaban contaminación bacteriana por los géneros Streptococcus spp. y Staphylococcus spp. También había presencia de bacterias de la familia Enterobacteriaceae, como los géneros Salmonella sp. y Klebsiella sp., y de la especie Escherichia coli, aunque la gran mayoría de los alumnos afirmó que los dispositivos estaban limpios.
\end{abstract}

Palabras clave: Estudantes; Smartphone; Staphylococcus aureus; Enterobacterias.

\title{
1. Introdução
}

No século XXI o celular é um dos aparelhos mais utilizados no cotidiano do ser humano, por sua praticidade em um compartimento pequeno e de fácil locomoção, por esses motivos é levado para muitos ambientes, por exemplo, hospitais, restaurantes, banheiros (Sousa et al., 2020; Mushabati et al., 2021). Essa facilidade de transporte acaba sendo meio de contaminação por patógenos, muitas vezes da microbiota normal do organismo, ou por contaminação externa (Silva, 2017).

Porém, o telefone pode ser considerado um dos principais fômites de doenças, como: diarreias, infecção intestinal e pneumonia, pois, pode ser contaminado por microrganismos patogênicos que infectam os seres humanos causando alterações em seu organismo (Nunes \& Siliano, 2016; Carvalho et al., 2021).

A transmissão de microrganismo do aparelho para o corpo humano acontece no momento em que ocorre uma aproximação da cavidade nasal, bucal e com a pele. Dentre os patógenos circulantes no aparelho, os mais comuns são bactérias, destacando-se as bactérias S. aureus e S. epidermidis e Escherichia coli, sendo a S. aureus resistente a oxacilina, penicilina G, meticilina, entre outros (Mendes, Pereira \& Rezende, 2014). Essa resistência é determinada, na maioria das 
vezes, por um gene localizado no cromossomo. Tais microrganismos são causadores de enfermidades, como: diarréia, infecção intestinal, meningite, pneumonia e inflamações na garganta (Mimica \& Mendes, 2017).

Em um estudo iraniano foi avaliado um número " $x$ " de trabalhadores da área de saúde para averiguar a contaminação bacteriana do aparelho celular, foi descoberto que boa parte dos microrganismos que estão presentes nos celulares pertence à microbiota normal da pele contendo agentes não patogênicos, e patogênicos. Uma porcentagem dessa amostra deu positiva para agentes patogênicos, como por exemplo, Enterococos spp, S. aureus e K. pneumonia (Cunha et al., 2016).

Boa parte desses estudos mostra a ausência de higiene dos usuários em relação ao celular, principalmente, através de análises bioquímicas que detectam a presença de coliformes fecais e totais, o que confirma a utilização do aparelho em toaletes que tiveram resultados positivos. Para ter uma higiene saudável é essencial manter as mãos limpas, sempre lavar com água e sabão antes de se alimentar, após ir ao banheiro e ao chegar da rua para retirar micróbios que podem causar enfermidades ao manipular o aparelho (Nunes \& Siliano, 2016).

Contudo, para evitar a contaminação existem alguns agentes sanitizantes que esterilizam o aparelho e do usuário que ajudam a manter a higiene do adequada, como: Álcool 70\%, álcool em gel, álcool contendo desinfetante, água e sabão (Manning et al., 2013). É importante lembrar que outra forma de diminuir a contaminação do telefone móvel é evitando o uso dele em locais com população microbiana alta, com: hospitais, banheiros e laboratórios, evitar também o manuseamento em local de alimentação, para que não ocorra a contaminação de alimentos (Texeira \& Silva, 2017).

Sabe-se que existem microrganismos que podem ser encontrados nos mais variados lugares, inclusive no telefone móvel como bactérias (Lindsley et al., 2020; Martina et al., 2019). No entanto, dentre esses microrganismos encontrados nos celulares, alguns podem pertencer a microbiota humana ou podem ser níveis patogênicos e por fins causadores de alterações na homeostase do indivíduo (Byrd, Belkaid \& Segre, 2018; Tajouri et al., 2021). Portanto, considerando-se os níveis de contaminação microbiana destes aparelhos mundialmente utilizados, este estudo irá alertar sobre a transmissão de patógenos à comunidade. Dessa forma, o presente trabalho objetivou identificar os microrganismos presentes em aparelhos celulares de acadêmicos de saúde de um Centro Universitário de Recife - PE.

\section{Metodologia}

Trata-se de pesquisa exploratória transversal, aprovada pelo Comitê de Ética e Pesquisa da Faculdade Pernambucana de Saúde (AECISA) sob o parecer $\mathrm{n}^{\circ}$ 3.787.336. O estudo foi realizado em um Centro Universitário São Miguel (UNISÂOMIGUEL), para identificação de bactérias em aparelhos celulares.

Os aparelhos utilizados na pesquisa foram de estudantes universitários do curso de Biomedicina da referida instituição, que concordaram em participar e assinaram do Termo de Consentimento Livre e Esclarecido (TCLE), inicialmente foi aplicado um questionário para avaliar os hábitos quanto ao uso e a assepsia dos telefones celulares.

As amostras foram coletadas por meio de swabs estéreis embebidos em solução salina ( $\mathrm{NaCl} 0,9 \%)$, os quais foram passados pela tela, parte posterior, partes laterais, microfone e capa de aparelhos celulares por toda a extensão do aparelho. Após a coleta, os swabs foram acondicionados em tubos de vidro identificados, contendo salina peptonada esterilizada. Os tubos foram mantidos sob refrigeração (caixa térmica com gelo) e enviados, com um questionário, no prazo máximo de duas horas, ao Laboratório de Microbiologia, da UNISÃOMIGUEL, onde as amostras foram processadas.

Para o isolamento e a identificação dos microrganismos, foram semeados em Ágar Sangue (para diferenciar hemólise de bactérias Gram positivas e Gram negativas), posteriormente foi realizado o teste de Gram. As bactérias identificadas com Gram positivas foram realizadas o teste de catalase no intuito de identificar os microrganismos do gênero Staphylococcus e Streptococcus. As bactérias catalase positiva, foi realizado o teste da coagulase e fermentação do manitol (meio Ágar Manitol). 
As bactérias foram semeadas em Ágar EMB (meio seletivo para o crescimento de bactérias Gram negativas e diferencial para utilização de lactose) e posteriormente realizadas as provas bioquímicas (Teixeira \& Silva, 2017).

A susceptibilidade in vitro das espécies bacterianas prevalentes foi determinada pelo teste de difusão em disco. Após o preparo, a suspensão bacteriana foi semeada em ágar Müeller-Hinton. Após 16 a 18 horas de incubação, os halos de inibição do crescimento bacteriano foram medidos em milímetros, e os microrganismos classificados como sensíveis, intermediários, ou resistentes aos agentes antibacterianos testados.

Os dados foram observados e tabulados pelo programa estatístico, Excel 2013, e posteriormente expressos em tabelas e gráficos.

\section{Resultados e Discussão}

Foram coletadas 30 amostras de aparelhos celulares dos acadêmicos dos cursos de saúde, dentre as quais a idade média dos voluntários foi de 20 a 30 anos.

O Quadro 1 retrata os dados obtidos através da apuração dos questionários da caracterização quando a higienização das mãos, ao uso de celular em banheiro, assepsia e períodos que realizam este procedimento (Lindsley et al., 2020).

Quadro 1 - Caracterização dos acadêmicos com relação ao questionário aplicado.

\begin{tabular}{|l|c|c|}
\hline QUESTÕES & SIM & NÃO \\
\hline Você higieniza as mãos com frequência? & $90 \%$ & $11 \%$ \\
\hline $\begin{array}{l}\text { Você costuma lavar sempre as mãos ao chegar da rua e antes } \\
\text { de se alimentar? }\end{array}$ & $91 \%$ & $23 \%$ \\
\hline $\begin{array}{l}\text { Você utiliza o celular enquanto está no banheiro? } \\
\text { Você costuma comer com o celular próximo da comida? }\end{array}$ & $63 \%$ & $37 \%$ \\
\hline $\begin{array}{l}\text { Você entra no banheiro, e em seguida vai comer com o celular } \\
\text { ao lado? }\end{array}$ & $72 \%$ & $28 \%$ \\
\hline $\begin{array}{l}\text { Você sabia que os celulares transportam milhares de } \\
\text { microrganismos? }\end{array}$ & $100 \%$ & $36 \%$ \\
\hline Utiliza o celular no laboratório? & $64 \%$ & $38 \%$ \\
\hline $\begin{array}{l}\text { Você conhece alguma bactéria presente no aparelho celular } \\
\text { contaminado? }\end{array}$ & $62 \%$ & $37 \%$ \\
\hline \begin{tabular}{l} 
Você conhece algum sanitizante para esterilizar o celular? \\
\hline
\end{tabular} & $63 \%$ & \\
\hline
\end{tabular}

Fonte: Autores (2021).

Na apuração de dados através do questionário, cerca de $100 \%$ dos acadêmicos afirmaram saber sobre a presença de microrganismos nos celulares, mas mesmo assim utilizam o aparelho em locais inapropriados, podendo haver risco de contaminação por diversos micróbios. $11 \%$ dos acadêmicos não lavam as mãos antes das refeições, 63\% se alimentam com o celular ao lado, e $72 \%$ levam o celular para o banheiro, e em seguida levam o celular para mesa. $63 \%$ dos acadêmicos não 
Research, Society and Development, v. 10, n. 9, e26210918064, 2021

(CC BY 4.0) | ISSN 2525-3409 | DOI: http://dx.doi.org/10.33448/rsd-v10i9.18064

sabem sobre agentes sanitizantes para esterilização do celular, sendo a falta de higienização dos celulares e das mãos a causa mais comum de contaminação.

Foi observado crescimento bacteriano em $100 \%$ dos celulares coletados, semeados por swabs umedecidos em solução salina e semeados em meio Ágar sangue de carneiro. A presença de bactérias foi confirmada em todos os celulares (Figura 1).

Figura 1-. Crescimento bacteriano em Ágar Sangue de Carneiro.

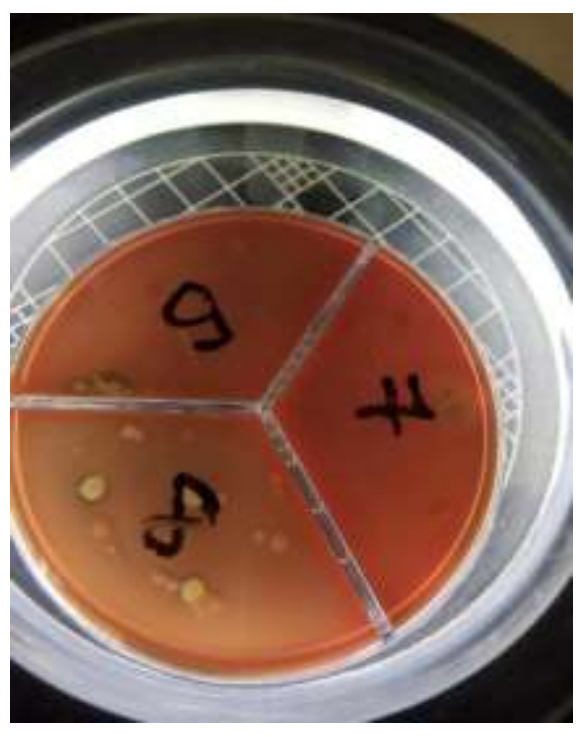

Fonte: Autores (2021).

Como resultado $100 \%$ aparelhos celulares coletados tiveram crescimento microbiológico, sendo $52 \%$ gram-positivas e $48 \%$ gram-negativas (Figura 2).

Figura 2 - Porcentagem das bactérias gram-positivas e gram-negativas presentes em aparelhos móveis dos acadêmicos.

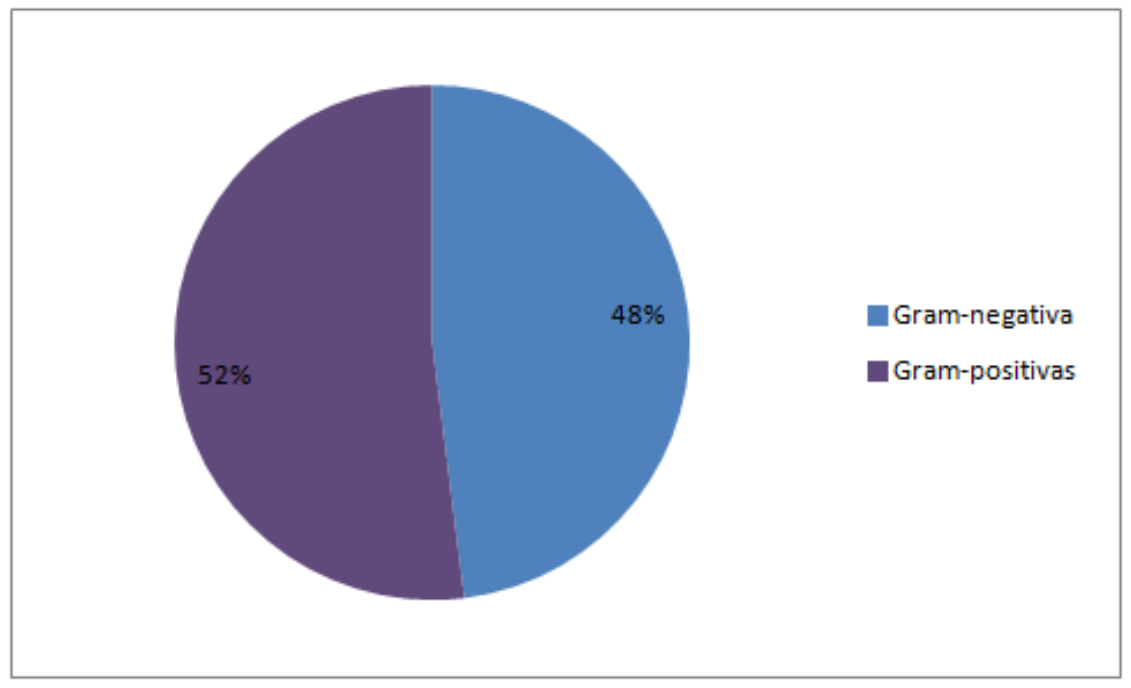

Fonte: Autores (2021). 
Os testes de catalase foram realizados em todas as placas, dando positivo para cerca de $48 \%$ dos celulares coletados, indicando assim a presença de Staphylococcus spp. Para os testes de catalase negativos foi-se observado a presença de hemólise nos meios de cultura, indicando a presença de Streptococcus spp. em $4 \%$ dos testes, porém quase todas as placas com crescimento bacteriano apresentaram hemólises dos tipos Beta, Alfa e Gama, podendo haver ambas as bactérias presentes nos celulares. O microrganismo mais presente foi Staphylococcus spp, o que corrobora com o estudo de Jimenez (2018) onde o gênero também foi o mais presente nos resultados, essas bactérias podem causar surtos alimentícios entre outras patogenias (Santana et al., 2020).

O estudo de Anjos et al (2017) também comprova a presença de espécies de Streptococcus spp como no presente estudo, o gênero possui cerca de 100 espécies conhecidas, apenas dos últimos 5 anos mais de 10 espécies foram encontradas. Podem causar infecções do trato respiratório, pele e tecidos moles, endocardites, sepse e meningites (Spellerberg \& Brandt, 2015)

Foi identificado em $30 \%$ dos celulares analisados, a bactéria Staphylococcus aureus, ao qual foi comprovado pela alteração na coloração do meio Manitol de rosa para o amarelado (Figura 3). A presença deste microrganismo pode ser explicada, devido a mesma ser comumente integrada à microbiota natural da pele, o que facilita na contaminação dos aparelhos, que constantemente são manejados (Texeira \& Silva, 2017). Entretanto, a S. aureus é um potencial patógeno quando encontrado fora da sua localização e/ou quando a imunidade se encontra baixa, uma vez que possui extenso fator de virulência, necessitando de atenção redobrada em seu monitoramento (Hanif; Hassan, 2019; Archer, 2020; Guo et al., 2020).

Figura 3 - Crescimento bacteriano em meio Ágar Manitol.

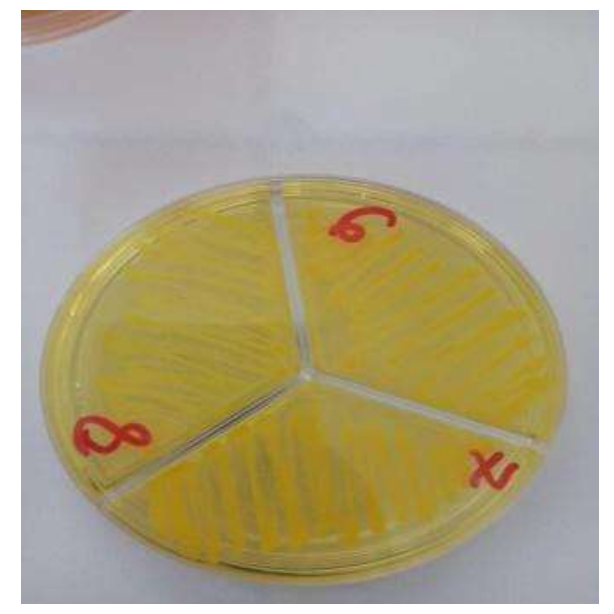

Fonte: Autores (2021). 
Figura 4 - Gráfico com as porcentagens das bactérias encontradas.

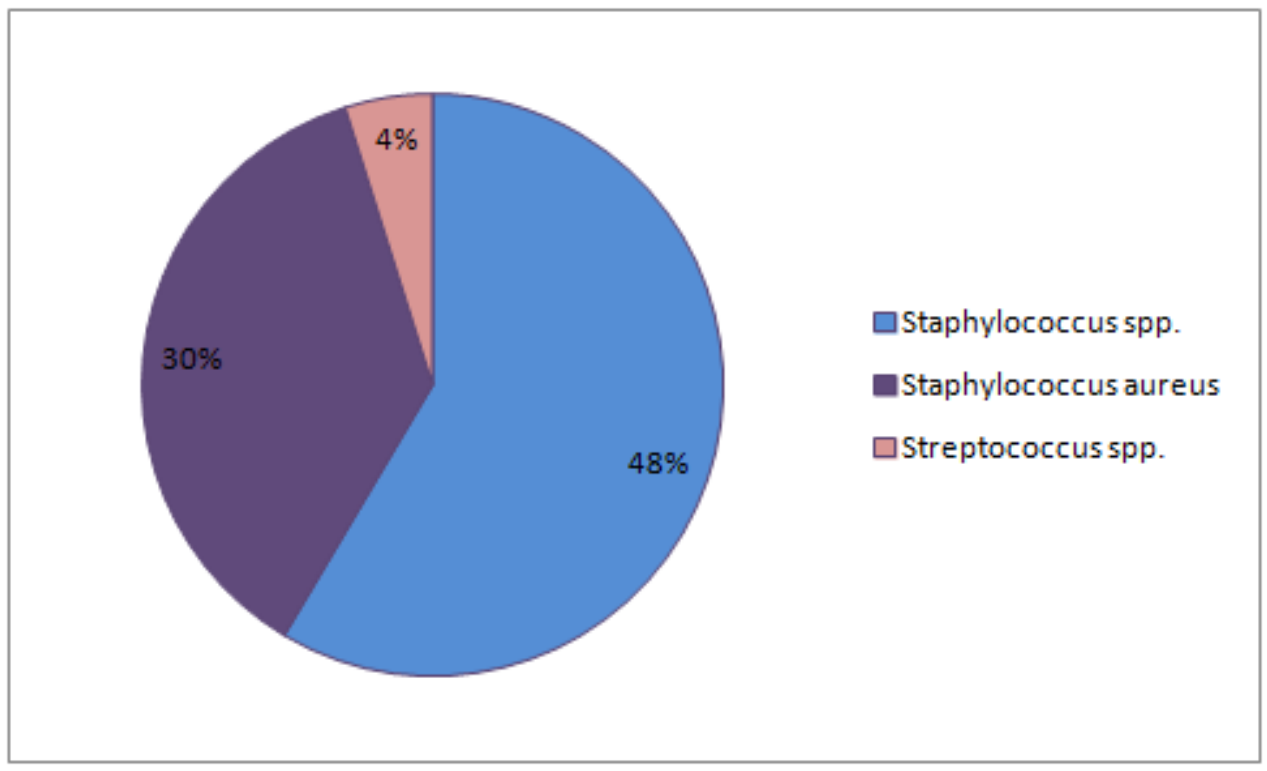

Fonte: Autores (2021).

De acordo com os resultados demonstrados, $48 \%$ das bactérias encontradas nos aparelhos de celulares foram Gram negativas (figura 1; figura 4), para a pesquisa de Enterobacteaceae foi possível identificar os gêneros Salmonella sp., Klebsiella sp., e a espécie Escherichia coli, as quais são naturais de regiões gástricas, porém se encontram presentes nos aparelhos e distantes da sua região natural, devido a sua utilização no momento da refeição e em banheiros. Santana et al. (2019), também observaram a ocorrência de E. coli na avaliação da microbiota de aparelhos celulares.

Na pesquisa de Araújo et al. (2017) 21 amostras foram positivas para Enterobactérias, os autores destacaram a presença dos gêneros Enterobacter sp., Klebsiella sp. e Pseudomonas sp, e relataram que a contaminação se dá principalmente pela falta sanitização correta dos aparelhos celulares.

No estudo de Texeira \& Silva (2017) foi possível identificar nos aparelhos as espécies Shigella sonnei, Yersínia enterocolítica e Escherichia coli, a ocorrência das Enterobactérias está associada ao hábito de usar os aparelhos em sanitários e não lavar as mãos.

Os resultados do antibiograma obtiveram variações na formação do halo, ao qual os que apresentaram halo menor a $18 \mathrm{~mm}$, representam bactérias mais resistentes aos antibióticos, e os halos acima de $22 \mathrm{~mm}$, representam as bactérias sensíveis (Nieto-Carhuamaca et al., 2019; Gonçalves et al., 2020). A partir dos dados obtidos, foi detectado mais bactérias resistentes aos antibióticos PEN e GEN10 em relação aos demais, assim como as bactérias foram mais sensíveis a EST10 e a TET30.

A única amostra que apresentou resistência bacteriana a todos os antibióticos foi a amostra 21, em que não houve formação de halo, que pode ser indicativo de bactéria multirresistente presente no celular. A explicação para os diferentes tamanhos dos halos, pode ser devido a variação de gêneros e espécies bacterianas encontrados nos aparelhos.

Por fim, é de grande preocupação por parte dos profissionais de saúde a higienização adequada das mãos para inviabilizar o contágio pelos patógenos fixados aos aparelhos celulares, assim como incentivam a desinfecção de objetos e superfícies antes do uso (Santos et al., 2002; Martina et al., 2019; Bhardwaj et al., 2020; Tajouri et al., 2021). Relacionado a isso, a resistência das bactérias encontradas aos diferentes antibióticos testados é resultante do constante uso indiscriminado e inadequado de fármacos antimicrobianos, que ao decorrer do tempo podem se tornar multirresistentes (Sánchez et al., 2015; 
Banawas et al., 2018). Dificultando não só a terapêutica, como também limitam as opções de tratamento de doenças (Guo et al., 2020; Carvalho et al., 2021; Felix, Medeiros \& Medeiros, 2018).

\section{Conclusão}

De acordo com os resultados obtidos, todos os aparelhos testados apresentaram contaminação bacteriana pelos gêneros Streptococcus spp. e Staphylococcus spp. Existem ainda a presença de bactérias da família Enterobacteriaceae como os gêneros Salmonella sp., Klebsiella sp., e a espécie Escherichia coli, mesmo a grande maioria dos acadêmicos afirmando a higienização dos aparelhos.

Conclui-se que a falta e/ou higienização inadequadas das mãos, tornam objetos do dia-a-dia, (como os celulares) fômites, objetos capazes de transmissão e desenvolvimento microbiano, que podem culminar em doenças. Sendo assim, é crucial que haja a desinfecção antes e após a utilização dos aparelhos, mãos e superfícies em ambientes que circulam várias pessoas, a fim de controlar a propagação de patógenos, assim como reduzir as chances de doenças infecciosas.

\section{Referências}

Anjos, P. P. D., Cavalcante, A., Queiroz, K. B., \& Bernadino, A. C. S. D. S. (2017). Espécies bacterianas isoladas a partir de telefones celulares uma revisão de literatura. Bio Medicina.

Araújo, A. M., Novais, V. P., Calegari, G. M., Góis, R. V., Sobral F. O. \& Marson, R. F. (2017). Ocorrência de microrganismos em aparelhos celulares no município de Ji-Paraná-Rondônia, Brasil. Brazilian Journal of Surgery and Clinical Research-BJSCR, 19, 10-15.

Archer, G. L. (1998). Staphylococcus aureus: a well-armed pathogen. Reviews of Infectious Diseases, 26(5), 1179-1181.

Banawas, S., Abdel-Hadi, A., Alaidarous, M., Alshehri, B., Bin Dukhyil, A. A., Alsaweed, M., \& Aboamer, M. (2018). Multidrug-resistant bacteria associated with cell phones of healthcare professionals in selected hospitals in Saudi Arabia. Canadian Journal of Infectious Diseases and Medical Microbiology, 2018.

Bhardwaj, N., Khatri, M., Bhardwaj, S. K., Sonne, C., Deep, A., \& Kim, K. H. (2020). Uma revisão sobre telefones celulares como reservatórios bacterianos em ambientes de saúde e potenciais abordagens de descontaminação de dispositivos. Pesquisa ambiental, $186,109569$.

Byrd, A. L., Belkaid, Y., \& Segre, J. A. (2018). The human skin microbiome. Nature Reviews Microbiology, 16(3), 143-155.

de Carvalho, J. J. V., Boaventura, F. G., da Silva, A. D. C. R., Ximenes, R. L., Rodrigues, L. K. C., de Almeida Nunes, D. A., \& de Souza, V. K. G. (2021). Bactérias multirresistentes e seus impactos na saúde pública: Uma responsabilidade social. Research, Society and Development, 10(6), e58810616303e58810616303.

Cunha, C. B. C., Moraes, F. R., Monteiro, V. S., Feitosa, F. G. M. A., \& Silva, I. T. C. (2016). Avaliação microbiológica dos aparelhos celulares de profissionais do Bloco Cirúrgico em um Hospital beneficente. Revista de epidemiologia e controle de infecção, 6(3), $120-124$.

del Pilar Sánchez, M., Gutiérrez, N. P., Padilla, M. Y., \& Suárez, L. L. (2015). Resistencia antimicrobiana de bacterias aisladas de clínicas veterinarias de la ciudad de Ibagué, Colombia. Universidad y Salud, 17(1), 18-31.

de Medeiros Felix, A. L., Medeiros, I. L., \& de Medeiros, F. D. (2018). Allium Sativum: uma nova abordagem frente a resistência microbiana-uma revisão. Brazilian Journal of Health Review, 1(1), 201-207.

Gonçalve, B. R., Tavares, R. S., de Assis, B. O., Júnior, E. E. G., \& Silva, V. C. C. (2020). Avaliação bacteriana em aparelhos celulares de acadêmicos e profissionais da área de saúde de uma faculdade localizada no sudoeste goiano. Research, Society and Development, 9(8), e79985380-e79985380.

Guo, Y., Song, G., Sun, M., Wang, J., \& Wang, Y. (2020). Prevalence and therapies of antibiotic-resistance in Staphylococcus aureus. Frontiers in cellular and infection microbiology, 10, 107.

Hanif, E., \& Hassan, S. A. (2019). Evaluation of antibiotic resistance pattern in clinical isolates of Staphylococcus aureus. Pak J Pharm Sci, 32 (4), 1749-1753.

Jimenez, L. (2018). Real-time PCR detection of S. aureus in pharmaceutical products. European Pharmaceutical Review, 23(6), 28-30.

Lindsley, J. A., Reynolds, C. D., Williams, T., Underwood, J., Ingram, A. N., Jowitt, J., \& Gelinas, L. S. (2020). How Dirty Is Your Phone? Evaluating Restroom Behavior and Cell Phone Surface Contamination. Joint Commission Journal on Quality and Patient Safety, 46(10), 588-590.

Martina, P. F., Martinez, M., Centeno, C. K., Von Specht, M., \& Ferreras, J. (2019). Dangerous passengers: multidrug-resistant bacteria on hands and mobile phones. Journal of preventive medicine and hygiene, 60(4), E293.

Mendes, A. B. G., Pereira, V. R., Rezende, C., Correspondente, A., \& Rezende, M. C. (2018). Aparelhos celulares: importante instrumento de Transmissão de patógenos na comunidade. 
Research, Society and Development, v. 10, n. 9, e26210918064, 2021

(CC BY 4.0) | ISSN 2525-3409 | DOI: http://dx.doi.org/10.33448/rsd-v10i9.18064

Mimica, M. J., \& Mendes, C. M. (2007). Diagnóstico laboratorial da resistência à oxacilina em Staphylococcus aureus. Jornal Brasileiro de Patologia e Medicina Laboratorial, 43, 399-406.

Mushabati, N. A., Samutela, M. T., Yamba, K., Ngulube, J., Nakazwe, R., Nkhoma, P., \& Kalonda, A. (2021). Bacterial contamination of mobile phones of healthcare workers at the University Teaching Hospital, Lusaka, Zambia. Infection Prevention in Practice, 3(2), 100126.

Nieto-Carhuamaca, A., Castañeda-Japan, J., Dámaso-Mata, B., Panduro-Correa, V., \& Arteaga-Livias, K. (2019). Bacterial resistance in cell phone cultures of medical students. Infez Med, 27(4), 374-379.

Nunes, K. O., \& Siliano, P. R. (2016). Identificação de bactérias presentes em aparelhos celulares. Identification of bacteria present of mobile phones. Science in health, 7(1), 22-25.

De Santana, E. H. W., Beloti, V., Aragon-Alegro, L. C., \& De Mendonça, M. B. O. C. (2020). Estafilococos em alimentos. Arquivos do Instituto Biológico, 77, $545-554$.

de Santana, V. T. P., Duarte, P. M., Fernandes, U. A., Damião, G. M., \& da Silva, A. L. (2019). Análise Microbiológica em Aparelhos de Celular de Acadêmicos e Professores da Universidade de Cuiabá (UNIC) Campus Primavera do Leste-MT. UNICIÊECIAS, 23(2), 105-109.

Santos, A. A. M. D., Verotti, M. P., SanMartin, J. A., \& Mesiano, E. R. A. B. (2002). Importância do álcool no controle de infecções em serviços de saúde. Rev. adm. saúde, 7-14.

Spellerberg, B., \& Brandt, C. (2015). Streptococcus. Manual de microbiologia clínica, 383-402.

da Silva, S. R. (2007). “Eu Não Vivo Sem Celular”: sociabilidade, consumo, corporalidade e novas práticas nas culturas urbanas. Intexto, (17).

Sousa, F. D. C. A., Mineiro, A. C. B., de Melo Araújo, R. F., de Oliveira, E. H., da Silva, W. C., de Sousa Rodrigues, L. A., \& de Siqueira Coelho, L. (2020). Detecção de bactérias em diversos locais em um centro universitário de ciências da saúde. Research, Society and Development, 9(2), e120921966e120921966.

Tajouri, L., Campos, M., Olsen, M., Lohning, A., Jones, P., Moloney, S., \& Alghafri, R. (2021). The role of Mobile phones as a possible pathway for pathogen movement A CROSS-SECTIONAL, MICROBIAL ANALYSIS. Travel Medicine and Infectious Disease, 102095.

Teixeira, F. N., \& Silva, C. D. (2017). Análise microbiológica em telefones celulares. Revista F@ pciência, 11(3), 15-24. 